\title{
Novel laparoscopic hernia of morgagni repair technique
}

\author{
Matthew L. Stone, MD, Matheau A. Julien, MD, PhD, Gansevoort H. Dunnington, Jr, MD, and \\ Christine L. Lau, MD, Charlottesville, Va
}

\begin{abstract}
A 44-year-old man presented to our institution with right heart failure. A previously active and healthy individual, he noted no significant medical or surgical history. His initial vital signs demonstrated no evidence of hemodynamic instability with a nasal cannula oxygen requirement of
\end{abstract} $5 \mathrm{~L}$. Arterial blood gas assessment revealed significant hypercapnea (partial pressure of carbon dioxide, $83 \mathrm{kPa}$ ). Chest radiography demonstrated right lower lobe collapse with possible compromise of the right hemithorax. Chest computed tomography confirmed a hernia of Morgagni with passage of colon, small bowel, and stomach into the thorax (Figure 1). Preoperative heart catheterization demonstrated elevated right atrial $(18 \mathrm{~mm} \mathrm{Hg})$ and pulmonary artery $(59 / 18 \mathrm{~mm} \mathrm{Hg})$ pressures. After optimization of his cardiopulmonary function, the patient provided written informed consent for laparoscopic hernia repair. Supraumbilical Veress needle entry into the abdomen achieved adequate pneumoperitoneum, and bilateral subcostal trocars were placed. The hernia contents were reduced without complication into an intra-abdominal position. After complete excision of the hernia sac to optimize visualization for mesh placement, an underlying $10-\times 7$-cm diaphragmatic defect was visualized with an absence of the anterior diaphragmatic rim. In the presence of insufficient innate diaphragmatic muscle for primary closure, a Prolene mesh prosthesis was created. Three 3-0 braided polyester sutures were placed in interrupted fashion into the anterior portion of the mesh before placement into the subdiaphragmatic space. A laparoscopic suture passer was inserted through corresponding stab incisions in the anterior abdominal wall, allowing retrieval and subsequent anterior diaphragm reconstruction (Figure 2). Three transfascial sutures provided optimal approximation of the mesh to the anterior abdominal wall with no deformation. Interrupted endostitch fixation to the native diaphragm achieved circumferential coverage with 2 to $3 \mathrm{~cm}$ of mesh-to-defect overlap. Staple deployment provided controlled layering of the mesh. Pneumoperitoneum was evacuated, and the patient was

\footnotetext{
From the Division of Thoracic and Cardiovascular Surgery, Department of Surgery, University of Virginia Health System, Charlottesville, Va.

Disclosures: Authors have nothing to disclose with regard to commercial support.

Received for publication May 14, 2011; revisions received July 7, 2011; accepted for publication July 25, 2011; available ahead of print Sept 19, 2011.

Address for reprints: Christine L. Lau, MD, Division of Thoracic and Cardiovascular Surgery, University of Virginia Health System, PO Box 800679, Charlottesville, VA 22908-0679 (E-mail: cll2y@virginia.edu).

J Thorac Cardiovasc Surg 2012;143:744-5

$0022-5223 / \$ 36.00$

Copyright (c) 2012 by The American Association for Thoracic Surgery doi:10.1016/j.jtcvs.2011.07.048
}

recovered. The patient followed an uncomplicated postoperative course with discharge on postoperative day 1 . He remained symptom free at 2 years postoperatively, with no baseline oxygen requirement or functional limitation.

\section{DISCUSSION}

The Morgagni-Larrey hernia constitutes 3\% of all diaphragmatic hernias that necessitate surgical repair. ${ }^{1}$ The triangular retrosternal foramen of Morgagni is formed by muscle fibers originating from the sternum and costal margin as they join the central tendon of the diaphragm. ${ }^{1}$ Incomplete congenital muscle fiber development predisposes patients to intrathoracic abdominal visceral herniation, with $91 \%$ of Morgagni hernias occurring on the right. ${ }^{2}$ Intrathoracic compressive symptoms are the predominant subjective complaint, with pulmonary limitations noted in $36 \%$ of patients. ${ }^{2}$ Our patient's presentation represents the potentially fatal cardiopulmonary compromise that can be imposed on patients with significant visceral herniation and intrathoracic compression.

Operative intervention for hernia of Morgagni at the diagnosis is supported because it limits the potential for visceral incarceration and subsequent requirement for a more challenging emergent surgical repair. ${ }^{1}$ Laparoscopic approaches to repair have provided diagnostic and

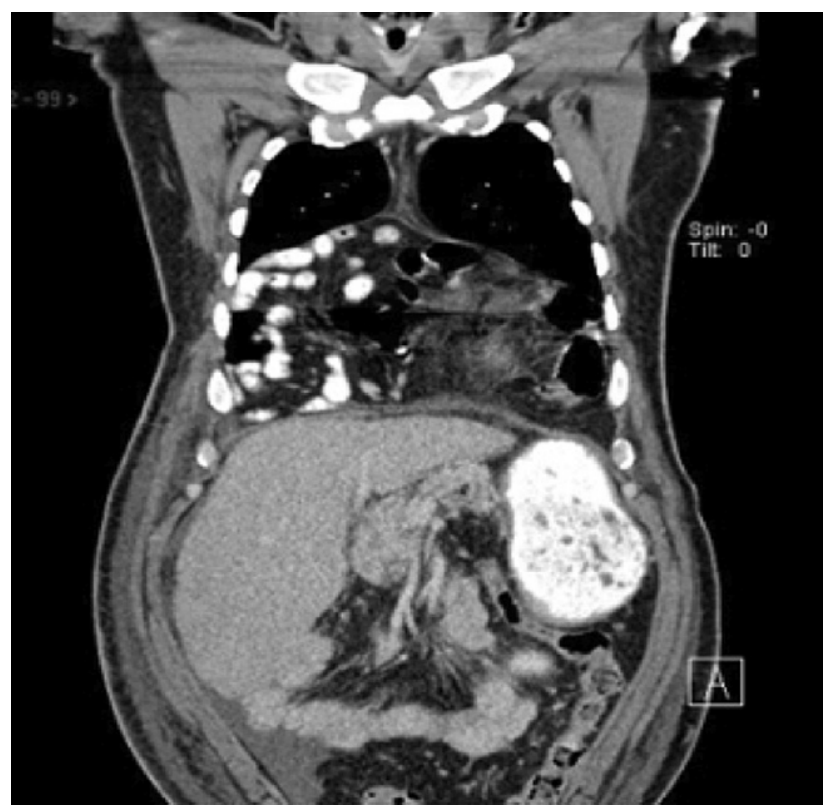

FIGURE 1. Chest computed tomography scan demonstrating hernia of Morgagni with displacement of stomach, small bowel, and colon into thorax. 


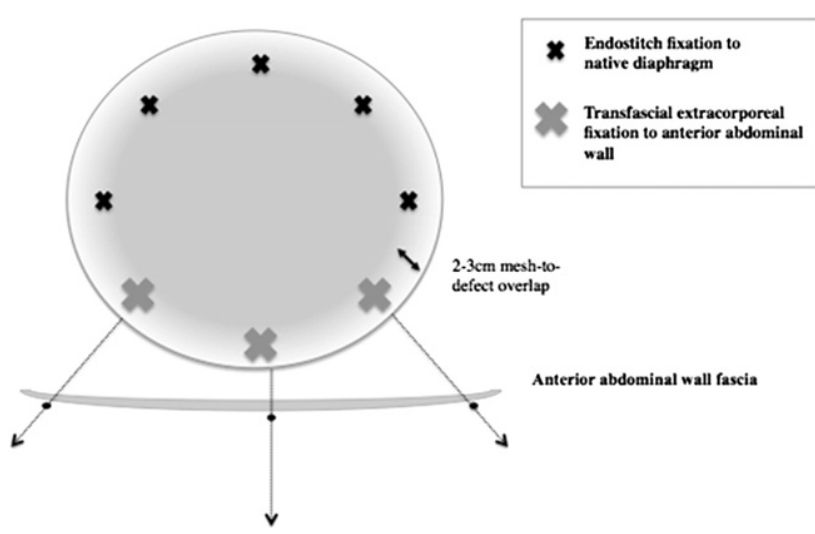

FIGURE 2. Diagram demonstrating mesh configuration in axial view with intracorporeal and extracorporeal knot orientation.

therapeutic advantages with shorter operative times, less postoperative pain, and an earlier return to full activity compared with traditional thoracotomy and laparotomy. ${ }^{3}$ Intraoperative evaluation of the presented patient revealed an absence of the anterior diaphragmatic rim, which inspired our use of the laparoscopic suture passer for retrieval of preplaced anterior mesh sutures. To our knowledge, this is the first report of laparoscopic suture passer use in the prosthetic repair of a Morgagni hernia.

Significant discussion persists regarding the appropriate technique for laparoscopic repair of the hernia of Morgagni. In meta-analysis, $64 \%$ have reported the use of a mesh prosthesis to achieve a tension-free repair, and $69 \%$ remove the hernia sac before closure of the defect. ${ }^{2}$ Successful repair has been achieved using laparoscopic-assisted extracorporeal and intracorporeal mesh prosthesis and primary repairs. ${ }^{4,5}$ No currently established guideline is available for the application of a mesh prosthesis, with reports of primary repairs of up to $50 \mathrm{~cm}^{2} .5$ Proponents of mesh repair have advocated universal application in defects $>20$ to $30 \mathrm{~cm}^{2}$ to achieve a tension-free repair, with 1.5 to $2.5 \mathrm{~cm}$ of overlap to the native diaphragm. ${ }^{3}$ Prolene mesh was chosen for our patient to accomplish dependable strength in repair of a defect with no directly adjacent bowel; however, a composite mesh might also be appropriate for this technique. Our experience with the successful repair of a large hernia of Morgagni supports the efficacy of hernia sac excision followed by laparoscopic-assisted prosthetic mesh reconstruction and extracorporeal knot fixation.

The laparoscopic suture passer provides a novel and adaptable method for prosthetic repair of the foramen of Morgagni. This technique allows direct visualization and controlled placement of the mesh prosthesis to the anterior abdominal wall. As we seek to better understand the mechanisms for Morgagni hernia development, laparoscopy promises to optimize our approach as a welltolerated diagnostic and therapeutic instrument for individualized care.

\section{References}

1. Minnecci P, Deans K, Kim P, Mathisen D. Foramen of Morgagni hernia: changes in diagnosis and treatment. Ann Thorac Surg. 2004;77:1956-9.

2. Horton JD, Hofmann LJ, Hetz SP. Presentation and management of Morgagni hernias in adults: a review of 298 cases. Surg Endosc. 2008;22:1413-20.

3. Thoman DS, Hui T, Phillips EH. Laparoscopic diaphragmatic hernia repair. Surg Endosc. 2002;16:1345-9.

4. Angrisani L, Lorenzo M, Santoro T, Sodano A, Tesauro B. Hernia of foramen of Morgagni in adult: case report of laparoscopic repair. J Soc Laparoendosc Surg. 2000;4:177-81.

5. Misra RP, Schwartz JD. A simplified technique of full-thickness transabdominal laparoscopic repair of Morgagni hernia. J Thorac Cardiovasc Surg. 2011;141: $594-5$.

\title{
Single-incision video-assisted thoracoscopic lobectomy: Initial results
}

\author{
Diego Gonzalez-Rivas, MD, ${ }^{\mathrm{a}, \mathrm{b}}$ Marina Paradela, MD, ${ }^{\mathrm{b}}$ Eva Fieira, MD, ${ }^{\mathrm{b}}$ and Carlos Velasco, $\mathrm{MD},{ }^{\mathrm{c}}$ Coruña, \\ Spain
}

\footnotetext{
From the Minimally Invasive Thoracic Surgery Unit, ${ }^{a}$ UCTMI, Coruña, Spain; and Departments of Thoracic Surgery ${ }^{\mathrm{b}}$ and Cardiovascular Surgery, ${ }^{\mathrm{c}}$ Coruña University Hospital, Coruña, Spain.

Disclosures: Authors have nothing to disclose with regard to commercial support.

Received for publication May 23, 2011; revisions received July 5, 2011; accepted for publication July 25, 2011; available ahead of print Aug 26, 2011.

Address for reprints: Diego Gonzalez-Rivas, MD, Department of Thoracic Surgery,

Coruña University Hospital, Xubias 84, Coruña 15006 Spain (E-mail: diego.

gonzalez.rivas@sergas.es).

J Thorac Cardiovasc Surg 2012;143:745-7

$0022-5223 / \$ 36.00$

Copyright (c) 2012 by The American Association for Thoracic Surgery

doi:10.1016/j.jtcvs.2011.07.049
}

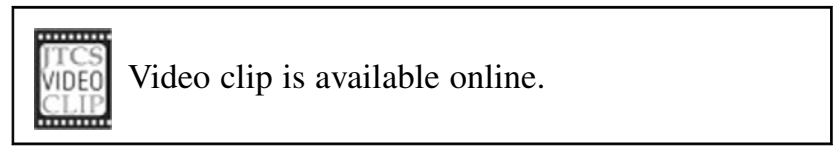

Video-assisted thoracoscopic surgery (VATS) was introduced nearly 2 decades ago and has experienced an exponential increase for lung cancer treatment. The standard approach is performed through three incisions, including a utility incision of about 3 to $5 \mathrm{~cm}$. However, anatomic 